Castellanos, N. (2016). Antropología de los silencios en la inminencia del conflicto armado. Revista de Sociología y Antropología: VIRAJES, 18 (1), 13-25. DOI: 10.17151/rasv.2016.18.1.2

\title{
ANTROPOLOGÍA DE LOS SILENCIOS EN LA INMINENCIA DEL CONFLICTO ARMADO*
}

\author{
NATALIA CASTELLANOS MARTÍNEZ**
}

Recibido: 9 de agosto de 2015

Aprobado: 28 de septiembre de 2015

Artículo de Investigación

\footnotetext{
* Artículo basado en la tesis doctoral "Los escenarios del miedo (Arauca-Colombia). Perspectivas desde la antropología cultural". Departamento de Antropología Social, Universidad Complutense de Madrid (2013).

** Antropóloga (2005) y Magíster en Antropología Social (2007) Universidad de los Andes (BogotáColombia). Doctora en Antropología Social y Cultural (2013) Universidad Complutense (MadridEspaña). Mención de Doctorado Europeo - Sobresaliente Cum Laude. Premio Iberoamericano de Ciencias Sociales Cortes de Cádiz (2014).natamaca@hotmail.com 이 ORCID: 0000-0001-9218-0106
} 


\title{
Resumen
}

El conflicto armado en Colombia ha sido el exponente más significativo de la violencia y también ha sido el conductor más claro del miedo, silenciando poblaciones y convirtiéndolo en un mediador de realidades. Cuando se utiliza el miedo como una herramienta para silenciar, se afectan profundamente las representaciones de las personas, sus modos de vida, sus sistemas simbólicos y sus tradiciones, revelando continuidades y transformaciones en las que el miedo y sus formas narrativas aparecen como expresión sensorial, respuesta y saber local. Si investigamos las diferentes expresiones del miedo y representaciones de los silencios más profundamente, podemos descubrir aspectos de la cultura que describen los grupos humanos y sus medios de adaptación.

Palabras clave: Silencios, conflicto armado, miedo, violencia, tradición oral.

\section{ANTHROPOLOGY OF SILENCES IN THE IMMINENCE OF ARMED CONFLICT}

\begin{abstract}
The armed conflict in Colombia has been the most significant exponent of violence and it has also been the clearest conductor of fear, silencing populations and turning it into a mediator of realities. When fear is used as a tool to silence, it profoundly affects representations of the people, their ways of life, their symbolic systems and their oral traditions, revealing continuities and transformations, in which; fear and narrative forms appear as a sensorial expression, a response and local knowledge. If we investigate the different expressions of fear and representations of silences more deeply, we can discover aspects of culture that describe human groups and their means of adaptation.
\end{abstract}

Key words: Silences, armed conflict, fear, violence, oral tradition. 


\section{Introducción}

L os resultados encontrados en la investigación que desarrollé a lo largo de mis estudios doctorales y el trabajo de campo realizado en zonas tanto rurales como urbanas del departamento de Arauca, zonas inmersas en complejas situaciones de orden público, ampliaron mis perspectivas de investigación en la medida en que me permitieron indagar sobre la población y las mutaciones de sus manifestaciones culturales. La incertidumbre y el miedo, así como las características de los espacios de muerte en la actualidad, se aunaron a mis cuestionamientos. La muestra etnográfica se amplió, entonces, a todo aquel que accedía a hablar sobre sus miedos. Las conversaciones transcurrieron en las tensiones que existen entre la voz y el silencio, entre lo que se cuenta y lo que se resguarda en las afonías.

Las entrevistas que se desarrollaron aquí a sujetos que viven en zonas de conflicto transcurren en sesiones colectivas e individuales, muchas veces con la ayuda de una grabadora de voz para el posterior estudio de las narraciones. Con frecuencia, los entrevistados fueron personas que han tenido que salir forzosamente de sus lugares de vivienda por amenazas contra su vida o que han sido víctimas de hechos violentos perpetrados por grupos armados de toda índole. Se trató de conocer sus vidas y experiencias, sus narraciones tradicionales y actuales sobre sus miedos, aunque en muchas ocasiones emergía una resistencia a develar las experiencias vitales que fueron silenciadas.

Fui muy respetuosa de los silencios, dado que, más que indagar a toda costa sobre estas vivencias que se callan, cuya revelación hubiese podido poner en peligro a mis informantes, lo importante era entender que la riqueza de las vivencias que ellos ocultan se encuentra precisamente en la falta de habla, en esa omisión de palabras. El reto del antropólogo en regiones afectadas intensamente por conflictos armados es el de ser intérprete, no solo de lo dicho, sino de lo que se omite. Para ello, debe demostrar agudeza en la observación del contexto y realizar un ejercicio de hermenéutica de los gestos, de las miradas, las actitudes, las atmósferas comunicativas, entendiéndolas como textos culturales complejos.

No se puede negar que, al querer indagar en las vidas, creencias y vivencias delos habitantes expuestos a la violencia, aparece de inmediatouna mordaza simbólica que los protege de las amenazas del entorno. Tampoco se puede ignorar la mordaza que el mismo investigador experimenta al estar inmerso en el mismo entorno comunicativo mediado por el miedo. Siempre está latente el temor de decir algo que traiga consecuencias negativas a las personas que colaboran con los trabajos casi arqueológicos de rastreo de 
datos y vestigios sepultados bajo esos silencios y esos temores.

$\mathrm{Al}$ reproducir en el diario de campo las conversaciones con diversas personas en cuya presencia es difícil sacar una grabadora de voz, es evidente que se logra un contacto verbal que consigna sus experiencias de la vida cotidiana mucho más fluida y cercana que cuando se utilizan dispositivos tecnológicos. Las anotaciones son eslabones fundamentales dentro de la recomposición del propio relato sobre el ir y venir de la estadía en campo. Sin lo escrito en el diario, hubiera sido imposible tener presente la filigrana de la narración. La recolección de la memoria del antropólogo como ejercicio de darle voz a sus propios miedos, ofrece pistas acerca de lo que se podría ocultar en esos lugares oscuros, silenciados por los agentes de la guerra; este ejercicio de interpretación del silencio propio puede arrojar luz sobre el ajeno.

El diario de campo constituye una herramienta crucial en ciertas situaciones en las que utilizar la grabadora de voz puede verse como una amenaza del investigador, cuando mostrarse "diferente", demasiado atento a alguna información, puede generar sospecha. Es necesario aprender el sutil arte de no generar un trauma adicional en la delicada urdimbre del entorno. En los contextos de violencia, esta pequeña máquina que graba voces y que se asocia con los periodistas causa alguna prevención $\mathrm{y}$, en muchas ocasiones, se convierte en un acto de ruptura total del vínculo comunicativo. De tal manera que el silencio es la mayor arma de supervivencia en estas zonas, y a través de él se accede a escuchar mucho más que cuando se pregunta con una grabadora de voz.

\section{Silencios}

La "abstención del habla" o la "falta de ruido" son las acepciones iniciales de lo que normalmente se entiende como silencio (DRAE, 22 ed.). Sin embargo, esta definición de diccionario es insuficiente cuando nos enfrentamos tanto al silencio propio como al de los otros, pues descubrimos que son múltiples sus estados y sentidos. Con la multiplicación de las representaciones del silencio, se hace necesario hablar de "los silencios", en plural. Como se verá, no podemos hablar de un solo silencio si miramos los complejos contextos y situaciones en los que emerge.

Existen situaciones en las que los silencios se complejizan, se cargan de nuevos significados según diversos usos que, al ser revelados, pueden mostrarnos una riqueza particular. Sin embargo, si no se pone en evidencia la riqueza de los silencios, se puede sumir todo sus significados en la 
oscuridad de la "abstención del habla", sin más. Los usos del silencio son variados: se emplea la palabra silencio, por ejemplo, para referirse a lo que no es posible nombrar, a lo inefable, a lo inexplicable, muy de la mano de lo metafísico. Sin embargo, los usos del silencio también tienen que ver con situaciones de violencia, con ejercicios desmedidos del poder. En los contextos de uso/abuso del poder, tanto víctimas como victimarios usan los silencios estratégicamente para reprimir o sobrevivir: los silencios son herramientas de supervivencia en contextos donde el habla puede implicar riesgo de muerte.

\section{La inminencia del conflicto armado}

En contextos de violencia, los individuos están expuestos a muchas formas de amenaza. La violencia impregna todos los ámbitos y se expande por la región, dividiendo comunidades y destruyendo sus vínculos tradicionales. El conflicto armado colombiano, por ejemplo, ha sido el más avasallador exponente de la violencia en este país y el más claro conductor de temores a lo largo del tiempo por varias generaciones, convirtiendo el miedo en mediador de realidades. Las situaciones de extrema violencia desatan sentimientos de vulnerabilidad, facilitando así la manipulación de la sociedad civil. Cuando el silencio acalla comunidades, cuando es manipulado con fines de control y poder, afecta profundamente las representaciones y las formas de habitar el contexto, debilitando política y emocionalmente a las poblaciones.

En las áreas donde se fractura el orden cotidiano del mundo por el miedo a las torturas, las masacres, las desapariciones, las muertes, se genera una constante sensación de miedo dentro de un mundo que se configura como inestable, ajeno, peligroso, "en donde el caos amenaza con desatarse en cualquier momento" (Scheper-Hughes, 1997, p. 213). Se empieza a desdibujar, con la violencia, el manto tácito de seguridad y orden de las comunidades. La violencia se traduce en inseguridad, totalizando los temores y las incomprensiones (Balandier, 1994, p. 191), la sensación de tranquilidad se rompe, pues se debe pensar tanto en factores cruciales y habituales de la vida cotidiana como en los "otros" factores no habituales, como es el caso de los agentes armados.

Los silencios van arropando en sus dominios realidades y acontecimientos, hechos violentos que, más que ser tangibles, reales y definidos, devienen "fuerzas oscuras", sorpresivas, ataques sin rostro, anónimos, que no se pueden reconocer ni nombrar, que se resguardan en el 
miedo que calla. Los dominios de los silencios enmudecen la memoria, una memoria que a largo plazo se irá extinguiendo en el olvido.

De la tensión entre lo dicho y lo que es silenciado, entre los saberes de diferente tipo y procedencia, es de donde se obtuvieron los datos etnográficos, fruto del trabajo de campo y del ejercicio de escuchar durante horas a personas que accedieron a responder mis preguntas. También, durante el ejercicio etnográfico, fue posible acceder a sonidos, sabores y olores que hacen parte de la vivencia del mundo y de los sentidos que les atribuyen los sujetos, en un ir y venir entre la observación y el análisis de comportamientos y discursos.

La población civil queda en muchas ocasiones en medio de los enfrentamientos, expuesta a los ataques con armas de fuego y explosivos, indefensa al no poseer ningún tipo de armamento. La cotidianidad se convierte en el escenario usual para la irrupción del terror, a través de escenas que desvirtúan todo significado de la muerte y en las que el silencio y la omisión de cualquier denuncia son el único seguro para continuar con vida.

Las poblaciones en Colombia "deben" explicaciones, simplemente por el hecho de haber tenido algún contacto con algún grupo armado. Es así como las comunidades se han ido convirtiendo en deudoras de fidelidades y de silencios; estas deudas han sido utilizadas para manipular, al no permitir que la población cree redes de conexión y solidaridad y quede "al margen" y a merced de los diferentes grupos, lo que siempre resulta en que quien obliga a dar respuestas, al final sea quien silencia.

La sospecha es como una infección, se extiende por poblaciones enteras en muchos casos, desatando masacres; por esto, el silencio es un punto crucial dentro de las estrategias de supervivencia. Al final, las personas quedan en deuda con todos los bandos por estar en medio de un conflicto armado y la violencia se ha transformado, entonces, en una deuda colectiva blindada por los silencios.

Dentro de los diferentes tipos de impotencia que genera la violencia dentro de la población civil está la del lenguaje, que se produce cuando las situaciones de angustia desbordan cualquier palabra y cuando la imposibilidad de hablar les da la esperanza de no repetir situaciones ni siquiera al nombrarlas. La impotencia y el silencio hacen parte de los momentos de crisis, dejan marcas en la memoria, desestabilizan las relaciones sociales y acrecientan la ambigüedad. Es una realidad en la cual la gente vive, un escenario de paradojas y contradicciones.

El miedo es una vía propicia para producir silencio: se entromete en todos los ámbitos de la vida, desde el ámbito familiar hasta el estatal, desde la relaciones interpersonales hasta las políticas. El miedo se vive a pequeña 
y gran escala; la conformación de la vida cotidiana que se construye en la dinámica de muchos encuentros y desencuentros con él se dinamiza por la superposición de lo mismo con lo "otro", dinámica en la que cohabitan lo familiar y lo extraño. El miedo se aloja allí, en la sospecha de la transformación de lo fraternal, y habita en los rincones más privados de lo que se solía llamar conocido y familiar. Cuando ni lo más cercano es seguro, se desprovee a la población de herramientas para enfrentar su entorno.

Una de las paradojas que viven los habitantes de zonas rurales y urbanas en contextos donde hay violencia y conflicto armado, es la convivencia con la sospecha acerca de quién será integrante de alguno de los grupos armados. La constante duda de que un familiar, un vecino, un amigo o un conocido sea una amenaza es parte de la vida diaria de estas personas. Los militantes de diferentes grupos pueden no poseer ninguna prenda o símbolo que los identifique, simplemente parecer una persona más, uno de los de siempre; pero todos tienen la particularidad - que representa un agravante en la convivencia- de ser potencialmente una amenaza para la vida de cualquiera.

Las tácticas de lucha de los grupos armados por el control de territorios se vuelven cada vez más inhumanas, y han llegado a límites inconcebibles e irracionales, incrementando el miedo en la población hasta lo insoportable y llevando a campesinos y habitantes de los pueblos al desplazamiento como única salida ante las acciones violentas, torturas y masacres. Hombres, mujeres, niños y ancianos se ven involucrados en una guerra sin tregua, en un conflicto sin razones evidentes de lucha social, en medio del caos y del sinsentido que produce la violencia incontrolada.

Cuando la vida cotidiana se militariza, los actores armados se involucran cada vez más en los ámbitos más seguros y familiares y abandonan su habitual contexto para convertirse en grupos que deambulan y que se inmiscuyen en los espacios de orden y protección y logran entrar más a fondo en las dinámicas de los hogares. Los grupos amenazantes que antes se caracterizaban por atacar y luego replegarse en las zonas selváticas o las montañas, ahora violan cada vez más los límites de las casas para resguardarse en ellas.

\section{NARRACIÓN VERSUS SILENCIOS}

Al investigar una comunidad que ha sido víctima del conflicto armado a través de un trabajo que he desarrollado durante años y que dio como resultado una tesis doctoral, pude entender como estos grupos humanos 
del departamento de Arauca han hecho del silencio su mejor arma de supervivencia, que tiene como insignia el "callar" y en la que el "silencio" invade todos los rincones - más aún los de la vida cotidiana- como método para hacer frente a la violencia del silenciamiento, se evidencian ejercicios de memoria en otro ámbito de la comunicación que hacen uso de una tradición que a la vez muestra y oculta realidades mezcladas con imágenes fantásticas, gracias al uso de lenguaje metafórico.

Se puede percibir la lucha incansable de estos grupos humanos contra el silencio a través de sus ejercicios narrativos, una mezcla entre ficción y realidad, inmersos en su tradición oral, que funciona como filtro, tamiz y prisma de realidades. Estos ejercicios narrativos constituyen una fuente riquísima de indicios, datos y subjetividades que se revelan a través de una forma de comunicación sin restricciones, ya que pueden ser expresados a viva voz sin ser una amenaza para nadie, pero iluminadores en la medida de tener el potencial de ser decodificados y comprendidos por los habitantes de la zona. La tradición oral está llena de códigos que trazan mapas de navegación al alcance de niños, adultos y ancianos, llenos de señales fundamentales y herramientas de supervivencia, una pedagogía ${ }^{1}$ en la inminencia de la violencia.

La labor del antropólogo se complejiza cuando la memoria está secuestrada en los silencios y se dificulta la comunicación. ¿Cómo acercarnos a las vivencias, creencias, tradiciones, si las voces son acalladas? Hacerse esta pregunta mientras el investigador mismo es instigado a silenciarse es un incentivo a ahondar mucho más en las condiciones de zonas tan complejas; aunque, por otro lado, al tener que contextualizar resulta ineludible tocar temas de violencia. Así, al preguntar sobre las narraciones tradicionales, es posible el acercamiento con menos prevención, pues al preguntar por las situaciones, vivencias o pensamientos alrededor de la violencia, se interpone entre los informantes y el investigador un muro difícil de penetrar. Acercándose a la comunidad desde un frente diferente a lo que para ella es más doloroso y avasallador, se muestran aristas que desde el abordaje directo de temas sobre la violencia no se hubiesen podido dimensionar.

$\mathrm{Al}$ acercarse poco a poco por las márgenes de lo folclórico, se puede llegar al vértice donde se unen los pensamientos y las costumbres tradicionales con las nuevas dinámicas del contexto, en donde se vislumbran por fin los mapas de la memoria. Estos mapas describen y transmiten

\footnotetext{
1 "Lo que quiero subrayar es que toda pedagogía ha de afrontar el reto de confrontar de modo crítico, pero amable, los prejuicios, los hábitos, las costumbres, las creencias, para que el sujeto mismo, partiendo de interrogaciones, asuma la sorpresa, la duda, la interrogación como una forma nueva de re/crearse, como el hábito por excelencia de la cultura" (Restrepo, 2004, p. 72).
} 
con intensidad realidades incrustadas en los pliegues de la memoria por medio de un lenguaje diferente, a través de seres fantasmagóricos que recrean realidades, acontecimientos, temores y advertencias que pueden ser replicadas y libremente comunicadas porque se sitúan dentro de la categoría de cuentos y ficciones, pero que en realidad contienen mucho de lo que sucede en un contexto actual. En muchos casos, la realidad supera la ficción, las historias que suceden a los habitantes superan lo que puede ser imaginado y son replicadas en los cuentos de espantos y aparecidos ${ }^{2}$, creando representaciones de doble sentido donde los victimarios, agentes armados, son personificados como seres de ultratumba que vuelven a la vida para seguir perpetuando la violencia.

En el ejercicio comunicativo de estas narraciones se desvía la atención hacia los dominios de la imaginación, pero lo que realmente está ocurriendo es una codificación de los significados esenciales para la supervivencia, camuflados entre los relatos de terror que han sido transmitidos por generaciones a través de su tradición oral. A través de las narraciones orales tradicionales, que son el conjunto de representaciones colectivas que se producen dentro de una cultura, se simboliza lo cotidiano. La tradición oral está fuertemente arraigada al entorno, la geografía, las personas, las tradiciones y las creencias. En ella se evidencian las formas en las que la gente ve su propio medio y su propia comunidad, y a partir de ella se informa cada individuo, y de generación en generación, acerca de acontecimientos que permanecen en la memoria. Dentro de la tradición oral existe el relato, es decir, "un conjunto articulado y coherente de enunciados, a través del cual se hace la relación de ciertos eventos de interés para el ser humano por medio de la palabra" (Galindo, 2003, p. 26).

En estos relatos se ven plasmados personajes y escenas determinadas en donde se transmite información por medio de un elaborado complejo simbólico que debe ser capaz de llegar a sus receptores de la forma más descifrable posible, mecanismos que hacen parte de lo cotidiano, de lo más habitual. La función del relato es permitir el contacto de la angustia sobre el personaje maléfico - ya sea encarnado en el demonio, los muertos, las almas en pena o las mujeres espectrales - ; gracias al relato, este personaje

\footnotetext{
${ }^{2}$ Por "espantos y aparecidos" me refiero a aparecidos como la visión de las imágenes de personas muertas. Estas imágenes de personas muertas están muy relacionadas con lo que María Cátedra ha descrito como espíritus entre los vaqueiros de Alzada (Asturias-España): “La definición de espíritu está basada fundamentalmente en sus manifestaciones. La presencia de uno de ellos se identifica en primer lugar por el miedo que producen; un temor incomprensible, una sensación de terror sin causa aparente, delata este tipo de fenómenos [...]. Además estos seres se perciben directamente por medio de los sentidos, el oído y la vista; siendo fundamentalmente más frecuente las manifestaciones que se captan por el primero. El espíritu produce una amplia gama de ruidos entre los que destacan las voces, gritos, lamentos, lloros o gemidos. Entre otras características, la teoría popular define al espíritu como 'cosas que suenan"'(Cátedra, 1988, p. 339).
} 
se ha hecho familiar, tiene una configuración dada, es una guía práctica, una causa que produce una regla moral y constituyen argumentos sociales. Los relatos son, entonces, parte integral de la cultura que van a predeterminar y dar orden a una realidad problemática.

En esta tensión entre palabras y silencios surgen mutaciones de los relatos tradicionales, contadas por personas que han crecido en el conflicto armado. Se puede observar cómo ciertas prácticas culturales se mantienen vigentes y enriquecen la memoria y sus representaciones, adjudicándoles nuevos significados a través de significantes igualmente nuevos: otras formas de contar la memoria. Estos relatos novedosos se distinguen de los tradicionales al incorporar escenas acompañadas de sucesos sangrientos, en su forma más extrema y aterradora.

Se narra una mezcla entre lo tradicional y nuevas experiencias de violencia, se confunde a propósito la realidad con lo fantasmagórico. Una confusión muy conveniente para la transmisión de cierta información que, de otra manera, quedaría oculta en los dominios de los silencios. Cuando se hace referencia a fantasmas y a personas que aparecen después de haber muerto, se refiere a personas asesinadas de formas violentas: degollados, ahorcados, gente que grita de noche, muertos que matan, secuestran y que vienen vestidos como guerreros, con trajes propios de militares, a los que nunca se les ve la cara, a quienes solo se les entrevé su perfil.

En cierta forma, a través de sus tradiciones, de su lenguaje y metáforas propias, se pretende dominar el entorno: "la bestia indomable de la violencia".

Las representaciones tradicionales de demonios y espantos fueron desbordadas por las prácticas de la guerra. Cuando la angustia rebasa cualquier palabra y cuando el silencio se convierte en protección, estas poblaciones luchan por controlar el miedo, mostrando la posibilidad de tener un conocimiento a priori de situaciones aterradoras dadas por los nuevos relatos. Estos son discursos alternos que se han movilizado colectivamente a través del "voz a voz", y que han generado procesos pedagógicos capaces de modificar sus habilidades adaptativas al tomar como modelo las experiencias aterradoras contemporáneas. En situaciones extremas, como la guerra, se toman medidas inéditas de transmisión de información que resultan fundamentales para conservar la vida. Se crea un fenómeno educativo no convencional de fácil alcance y seguro, que se actualiza con el contexto, formando modelos y un tipo de sujeto capacitado para enfrentar la violencia extrema. 


\section{En conclusión}

Estamos ante una poderosa forma de conocimiento que se reinventa frente a una situación social muy conflictiva y problemática, que estimula nuevas expresiones fantasmagóricas, vivas y presentes, que demandan la atención de la población, haciendo evidente el dolor, el daño causado, las pérdidas y el sufrimiento.

En el estado "liminal inconcluso" en el que permanece la comunidad, sin mecanismos de ajuste y reparación, en el que el dolor por las desapariciones, muertes, torturas, amenazas, desplazamientos, secuestros $\mathrm{y}$ abusos, hace surgir los relatos construidos a partir de fragmentos de emociones, de fragmentos silenciados y rescatados bajo máscaras. En estos relatos encontramos referencias simbólicas a bestias y seres monstruosos que representan su hábitat y su entorno, dinamizados en lo perverso, que estimulan una visión crítica, en la búsqueda de interpretaciones de lo complejo de sus vidas, que enriquecen las interpretaciones existentes y se enfrentan cara a cara al terror. "Lo que vamos a hacer con los monstruos es mirarlos de frente y dejarles que nos cuenten su secreto" (Lafuente, 2000, p. 18).

A continuación, tres de las diferentes narraciones de espantos que fueron consignadas en mi investigación, relatadas por los pobladores de Arauca que ejemplifican las nuevas mutaciones del miedo que le hacen frente a la fuerza del silenciamiento:

\section{NARRACIÓN 1:}

Andrés: Eso fue donde la mamá de Cecilia. Allá ha habido un muerto toda la vida, ahí mató una niña.

Cuando yo estaba así acostado, yo sí volví al conocimiento, y miré un hombre con vestido como esos guerreros, pero el alambrado no le dejaba agarrarme, dos o tres viajes a agarrarme por los pies pa' jalarme, y cuando llegó donde estaba la ceiba, y mirándole solo el perfil de donde estaba la cara, me llamó tres veces, y yo lo miré, cuando yo me di cuenta ya me tenían en la casa, metido entre una hamaca, amarrado, de tanto saltar me hubiera reventado.

Juan [A la esposa de Andrés]: ¿Por qué lo amarraron?

Esposa de Andrés: porque el muerto lo llamaba y se lo llevaba.

Andrés: Lo que sí le digo yo que esa vaina no pisaba el suelo, la cara no la veía, siempre de perfil.

Esposa de Andrés: Ese muerto llegaba a la casa y se lo llevaba de noche, a veces se acostaba uno y por ahí a las nueve lo escuchaba usted en una gritería, "¡no me lleve, no me lleve, yo no quiero ir, yo no quiero ir!", y él decía que era el muerto que lo agarraba por aquí, 
siempre por el lado del corazón.

Andrés: Sentía que me agarraba por aquí pa' jalarme, estaba dormido cuando me paraba pa' coger camino me despertaba, y el perro que estaba allí que no bajaba la guardia empezaba a ladrar. (Andrés, 36 años; Esposa de Andrés, 32 años; Juan, 45 años. Entrevista, 2 de marzo de 2006)

\section{NARRACIÓN 2:}

Aurelina: Es un hombre que ellos sentían cuando se acostaban en su chinchorro, ellos sentían un hombre embotado, o sea, en botas. Ellos sentían las botas, y así por todo el alrededor de la casa, lo sentían caminando y lo sentían caminando así alrededor del chinchorro de ellos, ellos dicen que ellos lo vieron. Los obreros dicen que sí lo miraban.

NC: ¿Qué podía hacer el hombre "embotado"?

A: Yo lo único que llegué a saber era que era un hombre que vivía por ahí cerca y lo habían matado. Le decían embotado porque lo miraban era con botas y se lo oía era con las botas, las botas era lo único que se sentía. Yo lo miraba era embotado, las meras botas. Como si fuera un guerrillero, precisamente, eso es así, y al lado de la finca eso tenían puro plátano y la mayoría pura coca, por allá por esa época había demasiada coca, y había mucha coca y precisamente en el campamento donde estaban los raspachines ${ }^{3}$, porque eso era muchísimo, eso eran 60, 70 raspachines, y eso que era que casi todos los días ese hombre ahí, en las noches. (Aurelina. Entrevista, 14 de octubre 2010).

\section{NARRACIÓN 3:}

Juan: Cuando se miró un jodido que salió de allá del palo [árbol] así, pa' abajo, un cuerpo, la pura joda que venía bajando por el palo. Un viejo, no se le miró cabeza ni nada, un cuerpo que venía bajando ahí, y eso sí es cierto. Ahí en Chaparral, nos salió un viejo guindado [colgado].

Braco: Ahí colgó a más de uno ese colgado.

J: Asustó a más de uno.

Carlos: Por ahí no paso de noche, entre más corre más se asusta, el miedo lo priva (quedar inconsciente). Es un muerto el que hay allí. El otro día fuimos al conuco a arrancar una yuca, y apenas pasamos, yo oí que hizo esa joda: "mmm...".

(Juan, 45 años; Braco, 62 años; Carlos, 40 años. Entrevista, 10 de febrero de 2006)

\footnotetext{
${ }^{3}$ Se refiere a los encargados de arrancar las hojas a la planta de coca para su posterior procesamiento.
} 


\section{Referencias bibliográficas}

Balandier, G. (1994). El desorden. Barcelona: Gedisa.

Cátedra, M. (1988). La muerte y otros mundos. Madrid: Ediciones Júcar.

Galindo, M. (2003). Mitos y leyendas de Colombia, tradición oral indígena y campesina. Bogotá: Círculo de lectores.

Lafuente,A. (2000). ¿Qué se puede hacer con los monstruos? En Lafuente A. y Moscoso J. (eds.), Monstruos y seres imaginarios en la Biblioteca Nacional. Madrid: Biblioteca Nacional / Doce Calles.

Restrepo, G. (2004). Arqueología de la urbanidad de Carreño, los oficios de un rastreador y baqueano de la cultura. Bogotá: Universidad Autónoma de Colombia / Instituto Superior de Pedagogía.

Scheper-Hughes, N. (1997). La muerte sin llanto. Violencia y vida cotidiana en Brasil. Barcelona: Ariel. 